\title{
An interesting case of intramyometrial pregnancy
}

\author{
Tina Verghese, Karim Wahba, Ahmar Shah \\ Obstetrics and Gynaecology Department, Yeovil district Hospital NHS Foundation Trust, Somerset, UK
}

Correspondence to Dr Tina Verghese, tinatycoon@yahoo.com

\begin{abstract}
Summary
A 27-year-old woman, gravida 3, para 1, at 9 weeks gestation, initially presented with clinical and ultrasonographic features suggestive of a missed spontaneous abortion for which surgical evacuation was performed. A diagnosis of ectopic pregnancy was made as on histological review no fetal or chorionic tissue was seen. Medical management for an ectopic pregnancy was initiated. Following methotrexate administration she was readmitted with severe abdominal pain. Findings on diagnostic laparoscopy revealed an asymmetrically enlarged swollen fundus. Hysteroscopy was performed concurrently demonstrating an empty uterine cavity. A diagnosis of intramyometrial pregnancy was made based on these findings. An MRI scan was performed postprocedure which supported the diagnosis. In view of her parity and future fertility medical management was adopted with methotrexate. She was followed up until hormone levels returned to baseline and serial scans showed a healed solid collection.
\end{abstract}

\section{BACKGROUND}

Intramural ectopic pregnancy is among the rarest forms of ectopic pregnancies. It was first described by Doderlien et al in 1913. ${ }^{1}$ Intramural pregnancy represents an unusual form of conception in which the gestational sac is located within the myometrium without any connection to the endometrial cavity, fallopian tubes or round ligament.

We report this case, as it must be kept in mind as an important differential diagnosis pertaining to ectopic pregnancy. Intramural pregnancies can be difficult to diagnose and can sometimes be missed. Early management of patients with unruptured ectopic pregnancies would give these patients the chance to preserve their fertility.

\section{CASE PRESENTATION}

A 27 -year-old Caucasian lady, gravida 3, para $1+1$, presented to the accident and emergency department at 9 weeks gestation with fresh vaginal bleeding. Her first pregnancy was a normal vaginal delivery with no complications. The second pregnancy was a spontaneous spontaneous abortion at 6 weeks gestation. Her medical history was unremarkable.

An ultrasound scan demonstrated an irregular pregnancy sac within the uterus, $19 \mathrm{~mm}$ in diameter, with the fetal pole inside and no visible fetal pulsations. A diagnosis of missed spontaneous abortion was made. Surgical evacuation was performed and she was discharged the next day. The products of conception were sent for histological analysis.

Histological review demonstrated that the specimen did not contain fetal or chorionic tissue, so the possibility of an ectopic pregnancy was considered. The patient was called back to be reassessed.

At reassessment she was asymptomatic though her $\beta$ human chorionic gonadotropin ( $\beta$-hCG) was 836 IU. An ultrasound scan showed a gestational sac of $44 \mathrm{~mm}$ in diameter, with the fetal pole inside and no pulsations as seen in figure 1. The sac was located near the right cornu. Consequently a diagnosis of right-sided cornual ectopic pregnancy was suspected.

Medical management was discussed with and accepted by the patient. Methotrexate was administered with a single dose of $80 \mathrm{mg}$ given intramuscularly. Serial $\beta$-hCG measurements were monitored according to the local protocol. On day 7 the $\beta$-hCG level fell to $361 \mathrm{IU}$ and it was decided to follow her in the early pregnancy unit until the levels were less than 10 IU.

Two weeks later, she was readmitted to the hospital with lower abdominal pain. The $\beta$-hCG level was 116 IU. An ultrasound scan demonstrated the same findings.

\section{DIFFERENTIAL DIAGNOSIS}

A differential diagnosis of cornual pregnancy was suspected.

\section{TREATMENT}

A diagnostic laparoscopy was performed and the findings from this revealed an asymmetrically enlarged uterus with a swollen fundus. There was a small hemoperitoneum less than $20 \mathrm{ml}$, with adhesions between the omentum, bowel and uterine fundus. The fallopian tubes, ovaries and uterine cornuae appeared normal. The laparoscopic findings are exhibited in figure 2.

Hysteroscopy was undertaken concurrently revealing an empty uterine cavity. Consequently a diagnosis of intramyometrial ectopic pregnancy was made. An MRI scan was conducted the following day supporting the diagnosis as shown in figure 3 . In view of her parity and future fertility, it was decided to manage the patient medically with methotrexate. The $\beta$-hCG levels were monitored and after 7 days the level dropped to 13. She was discharged home following this. A repeat scan at that time demonstrated the same findings but the pregnancy sac was regressing. The $\beta$-hCG level was less than 10 IU on day 14. 


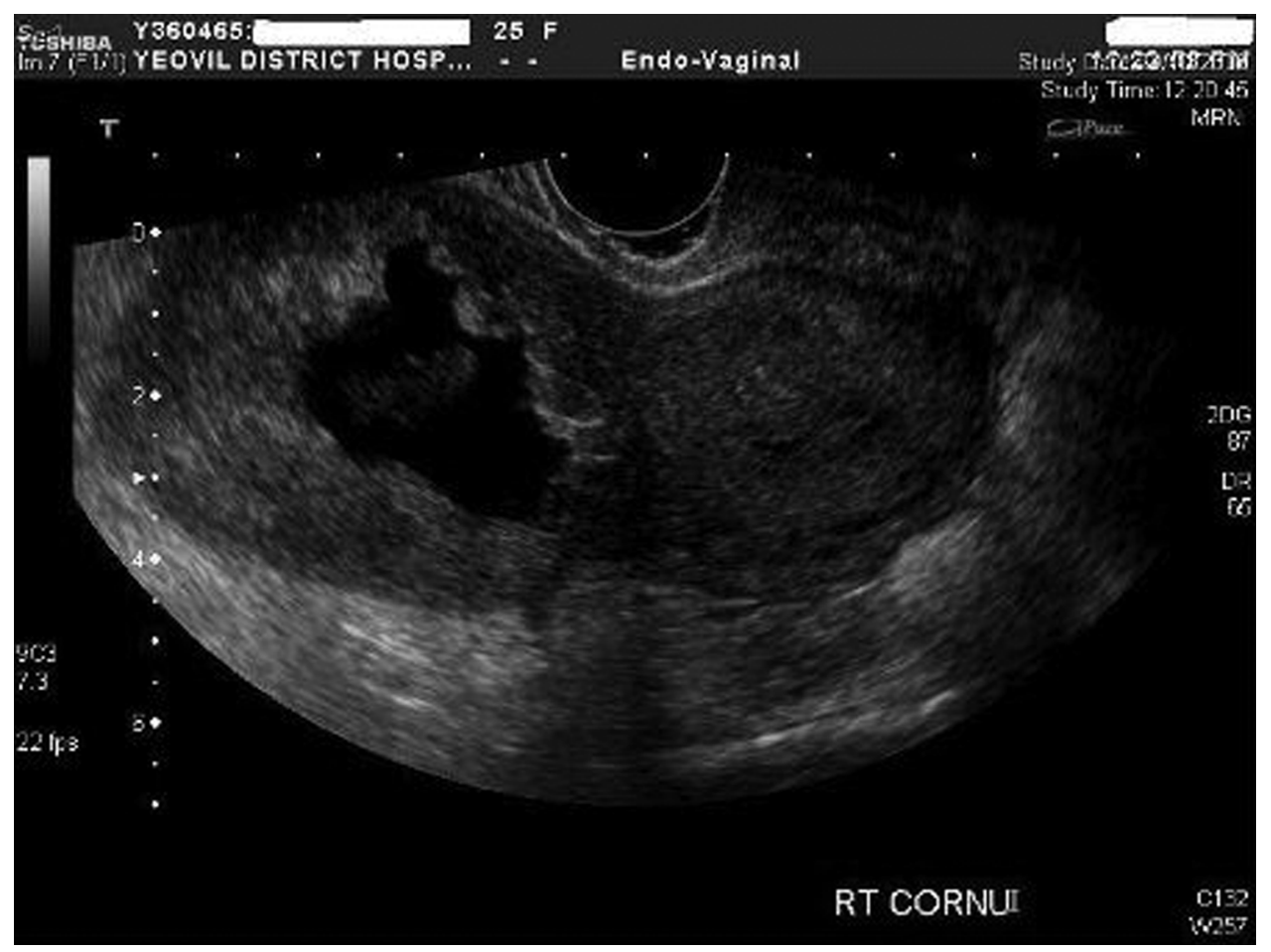

Figure 1 Ultrasound image shows an ectopic area within the fundus of uterus measuring $63 \mathrm{~mm}$ in diameter with an internal cystic collection measuring approximately $44 \mathrm{~mm}$ in diameter. Embryo was identified within the fluid collection. No fetal heart movement was demonstrated.

\section{OUTCOME AND FOLLOW-UP}

Due to the rarity of this case, the patient was closely followed up. She recommenced her menstrual cycle 1 month postadministration of methotrexate. A series of ultrasound scans were performed at intervals to monitor the regression of the gestational sac. Scans at 1 month and 6 months confirmed continued regression of the gestational sac, as demonstrated in figure 4, ultimately resulting in a healed solid collection.

\section{DISCUSSION}

Intramural ectopic pregnancy is among the rarest form of ectopic pregnancies. It was first described by Doderlien et al in 1913. ${ }^{1}$ It represents an unusual form of conception in which the gestational sac is located within the myometrium without any connection to the endometrial cavity, fallopian tubes or round ligaments.

As the pregnancy progresses, the gestational sac bulges from the serosal surface of the uterus with progressive thinning of the myometrium. This may lead to a uterine rupture and the need for a hysterectomy.

Maternal hemoperitoneum and hypovolemic shock are usually encountered with fetal wastage in most cases at 11-22 weeks gestation. ${ }^{2}$ Patients may remain asymptomatic until uterine rupture and massive haemorrhage develops. Common symptoms include vaginal spotting, pelvic pain and prolonged menstrual periods. In our case, the patient presented initially with vaginal bleeding.

A laparotomy with hysterectomy was the treatment of choice in most cases until the early 1990s. ${ }^{3}$ Following the development of ultrasonography, intramural pregnancies could be diagnosed before the gestational sac ruptured. A variety of conservative management options have reduced the need for unnecessary hysterectomies.

These methods include diagnostic laparoscopy, excision by mini laparotomy, hysterotomy by elective laparotomy, excision by operative laparoscopy and medical management with methotrexate. ${ }^{4-6}$

Methotrexate is a folate antagonist which targets rapidly dividing cells such as those in the placenta, thus making it a suitable treatment for ectopic pregnancies.

Treatment of extra uterine pregnancy with methotrexate has long been advocated. ${ }^{7}$ Since the 1980s medical management with methotrexate has been widely used for unruptured ectopic pregnancies. Systemic methotrexate has been suggested as an alternative method of treatment for an intramural pregnancy embedded in a uterine scar. ${ }^{8}$ This case describes the successful management of an intramural pregnancy with systemic methotrexate administration allowing for the preservation of reproductive potential.

There is limited evidence for the use of methotrexate in the treatment of non-tubal ectopic pregnancies. In our case, in view of her future reproductive potential and after discussing all the possible options, a decision was made to administer methotrexate. She was fully counselled regarding possible adverse effects that she may experience with the use of systemic methotrexate.

The diagnosis of intramural pregnancy is difficult to establish and can sometimes be missed. Using ultrasonography the intramural gestational sac may be missed as it is embedded within the myometrium which is an atypical location. In this case the initial ultrasound scan appeared to show a gestational sac within the uterine cavity with no fetal pulsations thus a diagnosis of missed 


\section{BMJ Case Reports}

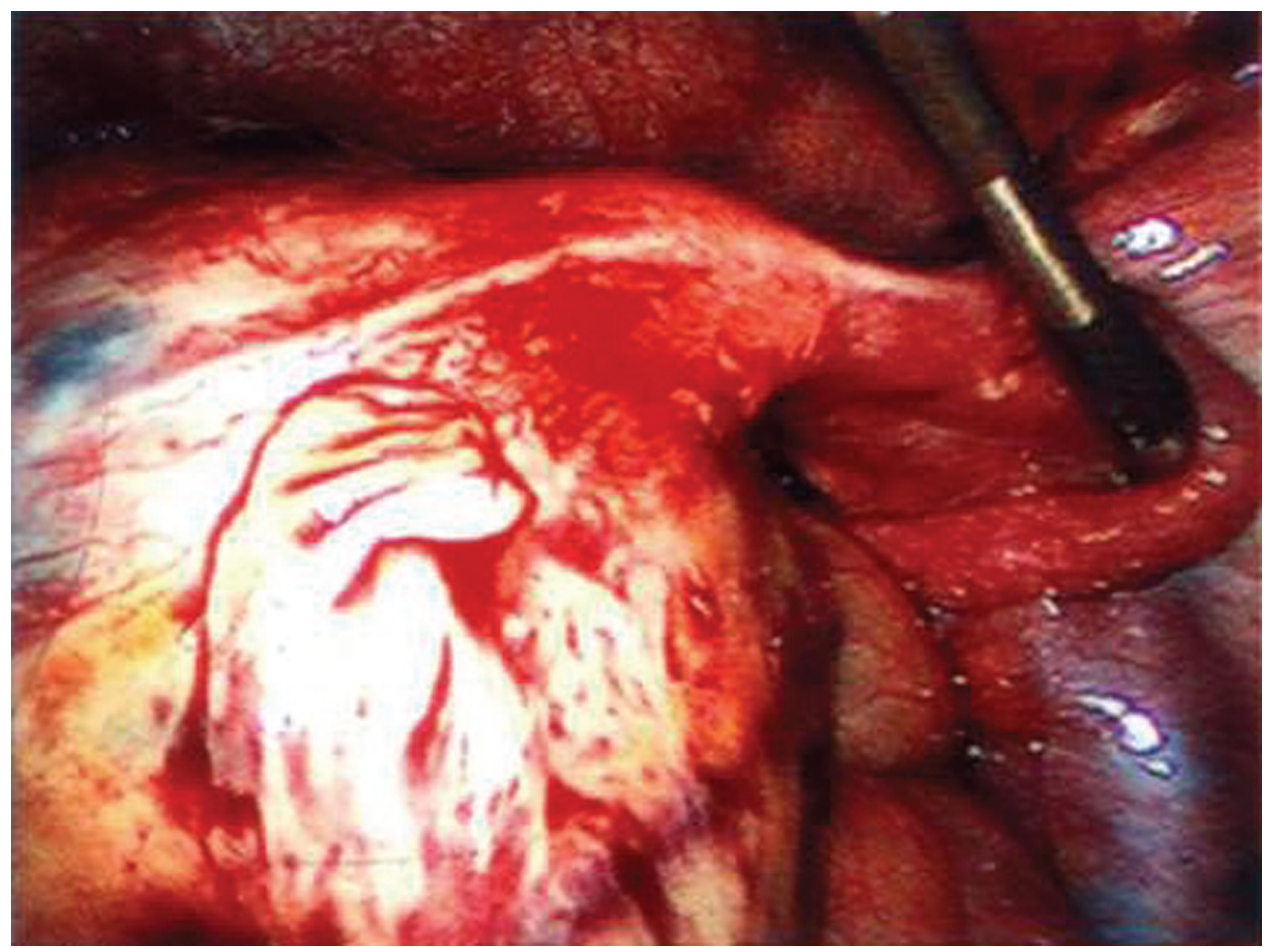

Figure 2 Diagnostic laparoscopic picture shows the enlarged swollen uterus at the fundus. A small haemoperitoneum and adhesions are present.

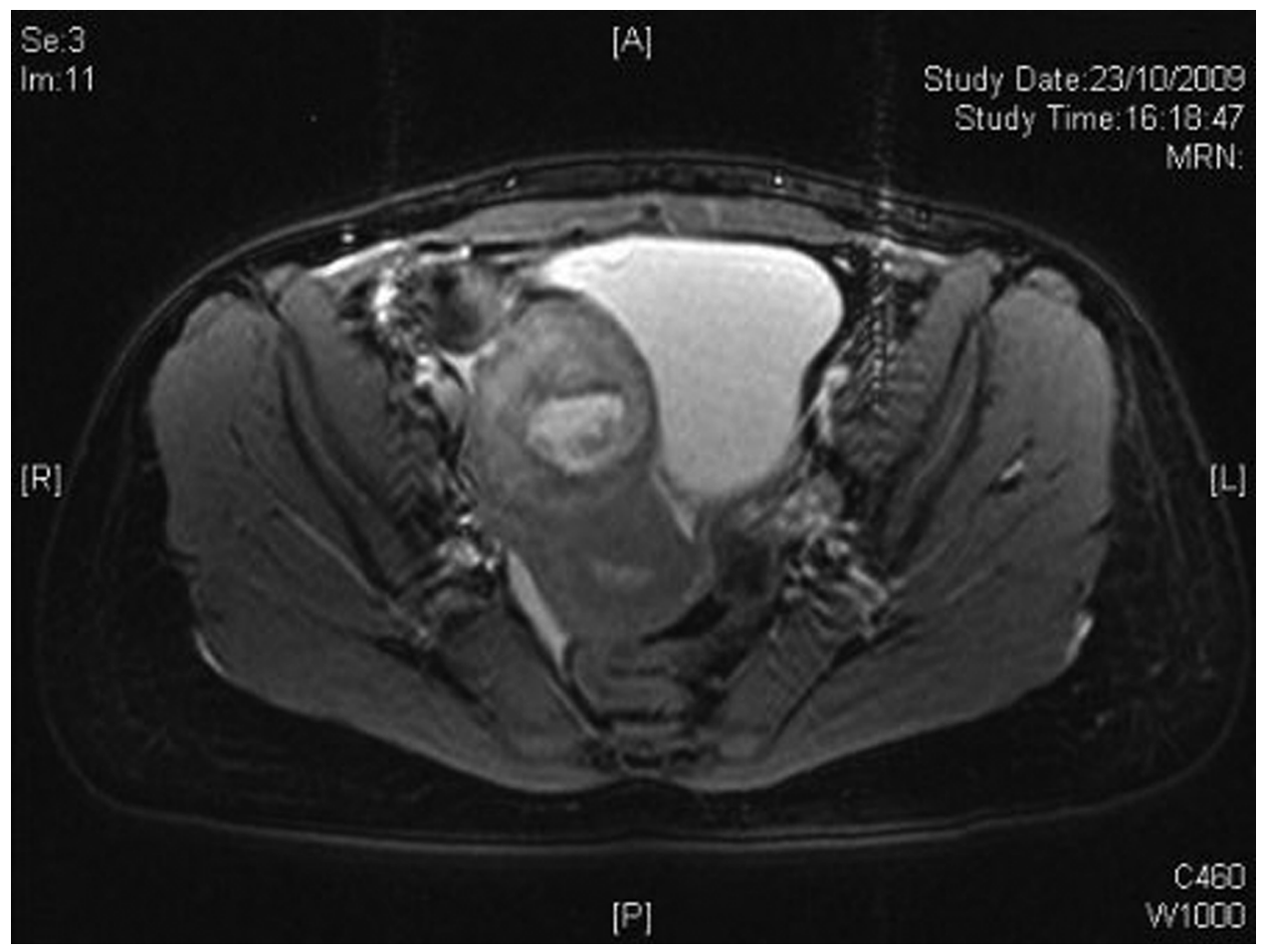

Figure 3 MRI image: series 3, image 11 Trufi sequence, 1.5 Tesla: image shows a normal endometrial cavity and fluid collection in the myometrium consistent with intramyometrial pregnancy.

spontaneous abortion was made. Absence of fetal tissue or chorionic tissue in the histological specimen prompted a repeat ultrasound assessment which diagnosed the case as a cornual pregnancy. The definitive diagnosis was determined after diagnostic laparoscopy which was undertaken in view of the sudden pain following treatment with methotrexate.

Use of 3-D transvaginal ultrasonography has been suggested as it may improve the accuracy of locating the gestational sac within the myometrium by producing multiple 


\section{BMJ Case Reports}

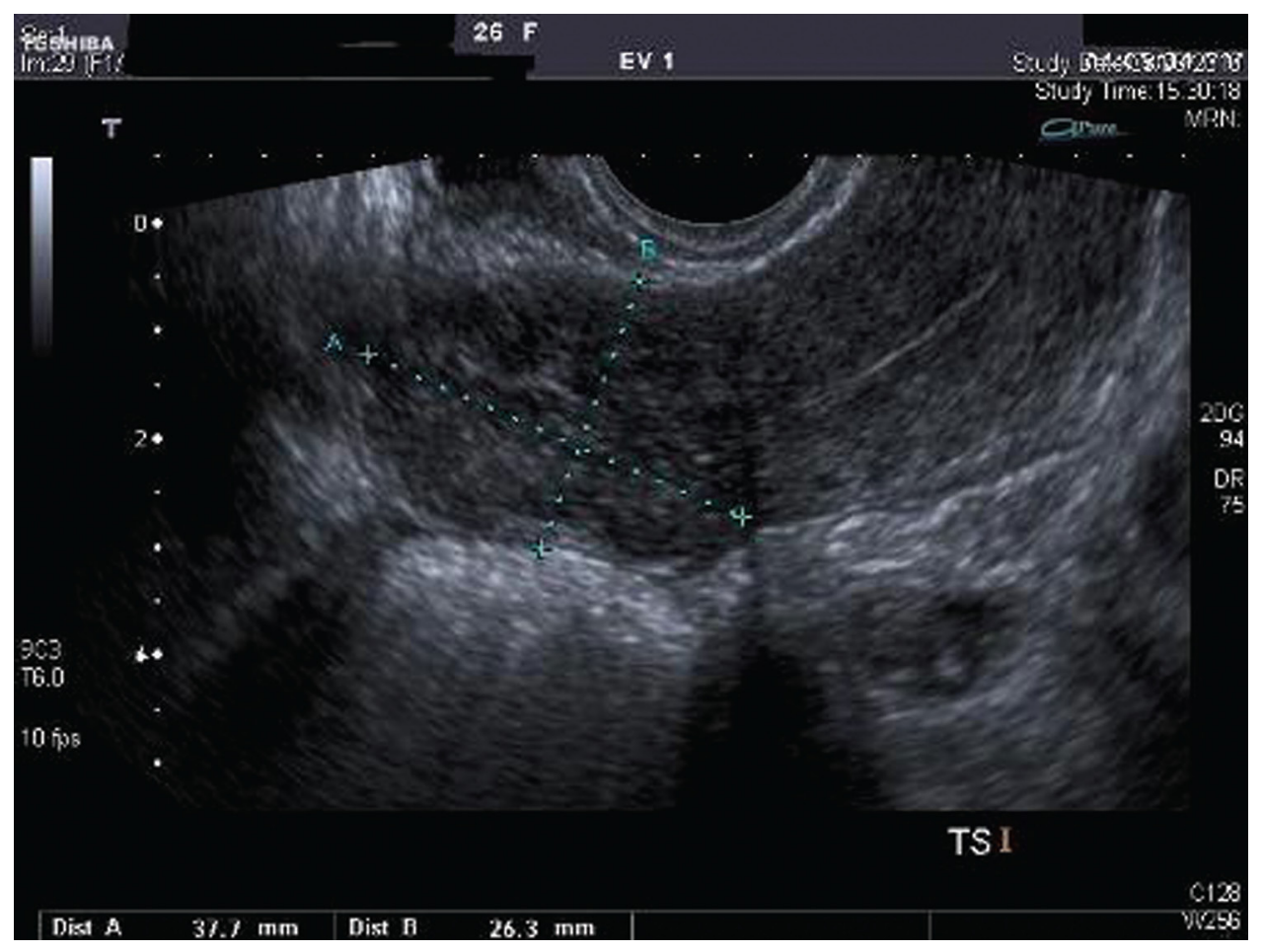

Figure 4 Ultrasound scan at 6 months shows a solid collection measuring $38 \times 26 \times 30 \mathrm{~mm}$ with no fluid component.

scans at different planes. The technique enables clear differentiation between the endometrium and myometrium enabling the gestational sac to be visualised readily. MRI has been suggested as an alternative non-invasive imaging modality, especially when the gestational sac has ruptured.

The diagnosis of intramyometrial pregnancy should be differentiated from interstitial ectopic pregnancy, pregnancy in a diverticulum, sacculation and a congenital uterine anomaly. On occasions, as in this case, diagnostic laparoscopy is necessary to differentiate intramural ectopic pregnancy from other differential diagnoses.

Several aetiologies have been proposed to explain the existence of this rare condition. Invasion of the myometrium through a microscopic tract was formed by previous uterine trauma resulting from procedures such as curettage, hysteroscopy or a caesarean section. Implantation in a focus of adenomyosis, increased trophoblastic activity and defective decidualisation can all result in intramyometrial pregnancies. ${ }^{9}$ Some cases were associated with invitro fertilisation and embryo transfer. In our case no risk factors were identified. We postulate that when the patient underwent evacuation of retained products, the products of conception were iatrogenically pushed into the myometrium. However, there is no evidence to confirm this.

With the dramatic increase in the number of suction curettages performed, clinicians may encounter more patients with intramyometrial pregnancies following uterine trauma. These patients should be followed with a high index of suspicious to detect this potentially catastrophic event in its earlier stages.

Prognosis is usually poor for fetuses in intramural pregnancies. Only one case in the literature has been reported when gestation continued without rupture for 30 weeks resulting in neonatal survival after caesarean hysterectomy.
The maternal death rate is approximately $2.5 \%$ when uterine rupture develops.

In conclusion, early detection of intramyometrial ectopic pregnancy in the asymptomatic woman has a special importance. Early management of these patients would give them the chance to preserve their fertility.

Learning points

- Intramural ectopic pregnancy refers to a uterine conception located within the myometrium without a connection to the endometrial cavity, fallopian tubes, or round ligament.

- The diagnosis of intramural pregnancy is difficult and can sometimes be missed. Diagnosis is usually difficult using ultrasonography, as it is difficult to distinguish an intramural pregnancy from an ectopic pregnancy at other sites. It may also mimic an intramural leiomyoma with cystic degeneration.

- It must be kept in mind as a differential diagnosis as early diagnosis and management in asymptomatic women with an unruptured pregnancy will give these patients the chance to preserve their fertility.

Competing interests None.

Patient consent Obtained.

\section{REFERENCES}

1. Lu HF, Sheu BC, Shih JC, et al. Intramural ectopic pregnancy. Sonographic picture and its relation with adenomyosis. Acta Obstet Gynecol Scand 1997;76:886-9.

2. Fait G, Goyert G, Sundareson A, et al. Intramural pregnancy with fetal survival: case history and discussion of etiologic factors. Obstet Gynecol 1987;70(3 Pt 2):472-4. 


\section{BMJ Case Reports}

3. Falfoul A, Jadoui A, Bellasfar M, et al. [Intramural pregnancy: a case report] J Gynecol Obstet Biol Reprod (Paris) 1992;21:641-3.

4. Seow KM, Hwang JL, Tsai YL. Ultrasound diagnosis of a pregnancy in a Cesarean section scar. Ultrasound Obstet Gynecol 2001;18:547-9.

5. Neiger R, Weldon K, Means N. Intramural pregnancy in a cesarean section scar. A case report. J Reprod Med 1998;43:999-1001.

6. Vial Y, Petignat $\mathrm{P}$, Hohlfeld P. Pregnancy in a cesarean scar. Ultrasound Obstet Gynecol 2000;16:592-3.
7. Palti Z, Rosenn B, Goshen R, et al. Successful treatment of a viable cervical pregnancy with methotrexate. Am J Obstet Gynecol 1989;161:1147-8.

8. Haimov KR, Sciaky TY, Naina N, et al. Conservative management of two ectopic pregnancies implanted in previous uterine scars. Ultrasound Obstet Gynecol 2002;19:616-19.

9. Ginsburg KA, Quereshi F, Thomas M, et al. Intramural ectopic pregnancy implanting in adenomyosis. Fertil Steril 1989:51:354-6.

This pdf has been created automatically from the final edited text and images.

Copyright 2012 BMJ Publishing Group. All rights reserved. For permission to reuse any of this content visit

http://group.bmj.com/group/rights-licensing/permissions.

BMJ Case Report Fellows may re-use this article for personal use and teaching without any further permission.

Please cite this article as follows (you will need to access the article online to obtain the date of publication).

Verghese T, Wahba K, Shah A. An interesting case of intramyometrial pregnancy. BMJ Case Reports 2012;10.1136/bcr.11.2011.5187, Published XXX

Become a Fellow of BMJ Case Reports today and you can:

- Submit as many cases as you like

- Enjoy fast sympathetic peer review and rapid publication of accepted articles

- Access all the published articles

- Re-use any of the published material for personal use and teaching without further permission

For information on Institutional Fellowships contact consortiasales@bmjgroup.com

Visit casereports.bmj.com for more articles like this and to become a Fellow

Keep up to date with all published cases by signing up for an alert (all we need is your email address) http://casereports.bmj.com/cgi/alerts/etoc 